neurobiology. If we accept the classical view of the axon as a passive distributor of impulses, then there appears to be a serious defect in its performance. In order to overcome this defect, the nervous system may form a large number of redundant connections so that intermittent failure of nerve conduction will not seriously hinder the processing of neural information. Alternatively, as Lettvin and his colleagues maintain (Brain Behav. Evol., op. cit: see also Waxman, Brain Res., 47, 269; 1972), the axonal tree may act as a filter, regulating the flow of impulses into one or other branch, depending on the temporal pattern of firing. It is quite common for a single nerve to innervate more than one type of post-synaptic cell, and if the axon is capable of controlling one or the other, or both, through its firing pattern, as demonstrated in the crustacean motorneurone, then what appears to be a fatal defect of the bifurcating axon may turn out to be a very useful property in achieving an economy in neural organisation.

\title{
Mysteries of early dinosaur evolution
}

\section{from Barry Cox}

Although many pages have been written discussing the mystery of the extinction of the dinosaurs, almost as much uncertainty surrounds their origin-or origins. The large Mesozoic archosaurian reptiles known as dinosaurs belong to two separate groups, the Saurischia and the Ornithischia, which differ in such characters as the structure of the pelvic girdle and the possession of a predentary bone (present only in ornithischians). A diversity of saurischians is known from the late Triassic, as are about six genera of ornithischians. But the relationships of the two groups to each other, or to the earlier Triassic archosaurians known as pseudosuchians, remain uncertain.

By the Early Jurassic, saurischians include at least two types. The small carnivores (or coelurosaurs) and the large carnivores (or carnosaurs) were both bipedal, and are both placed in a single group, the Theropoda. Late Triassic coelurosaurs are known, but no Triassic carnosaurs have yet been found. The other saurischian group, the Sauropoda, comprises the very large, quadrupedal, long-necked herbivores of the Jurassic and Cretaceous. Their Triassic ancestry runs back into an assemblage of quite large facultatively bipedal forms, the prosauropods, which include both herbivorous and carnivorous types. It is therefore at least possible that the coelurosaurs, the carnosaurs and the prosauropods all had quite separate origins from within the pseudosuchians. Various authors, such as Charig and Bonaparte, have suggested this, basing their views mainly on apparently divergent structural modifications of the ankle in these groups.

So far, at least, there has been less evidence of diversity in the Triassic ornithischians; only two, rather similar families are known. Smaller than most of the saurischians, their structure has been less well known, but an article by Santa Luca, Crompton and Charig in this week's issue of Nature (page 324) provides a preliminary account of an exceptionally fine specimen from the very late Triassic of South Africa. This little bipedal, fast-running herbivore, Heterodontosaurus, had already developed a number of specialised features, such as the grasping hand and some degree of fusion of the bones of the ankle. Ornithischians, then, had also clearly been evolving and radiating for some time before the end of the Triassic.

If one now attempts to relate these two types of dinosaur to the Triassic pseudosuchians, there appears to be a puzzling overlap in time between the two groups, although possible evolutionary links between them obstinately refuse to appear. Though the pseudosuchians include large bipedal carnivores, the ornithosuchids of the Middle and Late Triassic, which have been suggested as ancestral to the carnosaurian dinosaurs (Walker, Phil. Trans. R. Soc., B248, 53: 1964), this has since been denied by Bonaparte (Coll. int. Cent. nat. Rech. sci., 218, 485; 1975). The large Late Triassic quadrupedal pseudosuchian carnivores known as rauisuchids (or prestosuchids) have been nominated as the possible source of the saurischians, while the only pseudosuchian similar to the little ornithischian dinosaurs is the small bipedal genus Euparkeria of the Early Triassic.

The possible ancestors of the different types of dinosaurs are thus scattered through the Triassic, and the pseudosuchians persisted until the end of that Period. Throughout the Late Triassic, at least, a variety of pseudosuchians therefore coexisted with a variety of their presumed descendants, the dinosaurs, as has been pointed out by Sill (Bull. Mus. comp. Zoo. Harv., $146,317 ; 1974)$. The perhaps multiple evolution of dinosaur lineages therefore did not lead to the rapid ecological replacement of their pseudosuchian ancestors. These instead persisted, together with their relatives the semiaquatic phytosaurs and the pig-like rooting aëtosaurs, until the end of the Triassic, when all became extinct together-though no new ecological replacements for them appeared at that time.

So the poor palaeontologist searching for answers is therefore, in the origin of the dinosaurs, confronted with complexity where he hoped for simplicity, while in the replacement of the pseudosuchians by their varied offspring he meets a sudden (if delayed) simple event where he expected complexity! Today, the fashionable deus ex machina for explaining extinctions is continental drift, but even rising sea levels resulting from the beginning of the opening of the Atlantic in the Late Triassic seem unlikely to provide a solution to these puzzles.

\section{Future of the CERN intersecting storage rings}

from M. G. Albrow

A Workshop on Future ISR Physics was held at CERN, Geneva on October 4-15, 1976.

IN January 1971 two beams of high energy protons were trapped in the CERN Intersecting Storage Rings (ISR) and brought into head-on collision for the first time. This achievement enabled high energy physicists to study particle interactions, under well-controlled laboratory conditions, at energies otherwise accessible only with cosmic rays. The ISR beam energy ranges up to $31 \mathrm{GeV}$ : an accelerator of $2.000 \mathrm{GeV}$ would be needed to obtain the same effective collision energy using a particle beam on a stationary target. The present commissioning of the $400 \mathrm{GeV}$ SPS accelerator at CERN, and plans at the Fermi National Accelerator Laboratory to construct a $1,000 \mathrm{GeV}$ "Energy Doubler", have stimulated a reevaluation of the role of the ISR in high encrgy physics. There is no doubt that the ISR has a unique position in terms of available collision energy; the question is whether that advantage is important enough to guarantee an exciting programme of physics for many years to come, and therefore to justify its continued operation in the present financial climate. A workshop, attended 